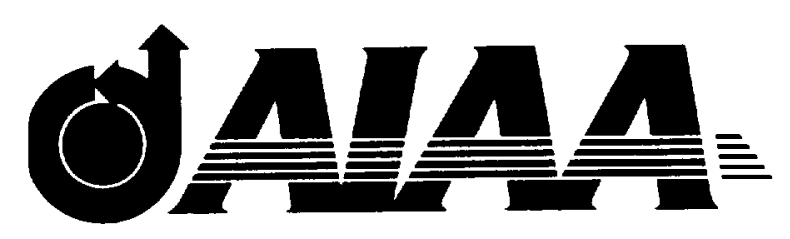

NASA-CR-202586

AIAA-95-1052

Effect of Gravity on the Mammalian Cell Deformation

R. Hung

The University of Alabama in Huntsville Huntsville, $\mathrm{AL}$

Y. Tsao

KRUG Life Sciences

Houston, TX

S. Gonda

NASA Johnson Space Center

Houston, TX

Life Sciences and Space Medicine Conference

April 3-5, 1995 / Houston, TX

For permission to copy or republish, contact the American Institute of Aeronautics and Astronautics 370 L'Enfant Promenade, S.W., Washington, D.C. 20024 



\title{
EFFECT OF GRAVITY ON THE MAMMALIAN CELL DEFORMATION
}

\author{
R. J. Hung*, Y. D. Tsao**, Steven Gonda*** \\ " The University of Alabama in Huntsville, Huntsville, AL 35899 \\ ** KRUG Life Sciences, Biotechnology Facility, Biotechnology Laboratories, Houston, TX 77058 \\ * Biotechnology Program, SD4, NASA Johnson Space Center, Houston, TX 77058
}

\section{Abstract}

The effect of human cell immersed in culture liquid under a microgravity environment has been investigated. The study is based on the numerical simulation of the configuration of human cell affected by the time dependent variation of gravity acceleration ranging from $10^{-3}$ to $2 g_{0}\left(g_{0}=9.81 \mathrm{~m} / \mathrm{s}^{2}\right)$ in 15 seconds. Both the free floating cell and the cell contacted to the upper and lower inclined walls imposed by the timedependent reduced gravity acceleration are considered in this study. The results show that the cell configuration changes from spherical to horizontally elongated ellipsoid for both the free floating cell and the cell sitting on the lower inclined wall while the cell configuration varies from spherical to vertically elongated ellipsoid for the cell hanging to the upper inclined wall when the gravity acceleration increases. Experimental observations, carried out in the $\mathrm{KC}-135$ free fall aircraft test of the deformation of human cells exposed to the variation of gravity levels, show that the results of experimental observations agree exactly with the theoretical model computation described in this paper. These results are significant for humans exposed to the microgravity environment.

\section{Introduction}

A variety of forces influence human cell shape. To name a few, these forces include osmotic and hydrodynamic pressure gradients for a cell of inherent compartmentalization to be utilized to promote transport and other functional processes as well as motile functions such as protrusions and blebbing. Surface tension between the cellular membrane and the eternal surroundings has been shown to play a potentially important role in cell shape, especially during deformation of spherical cells. The cytoskeleton, cellular membrane and attachments between the two create a cell which has certain viscoelastic properties including creep, relaxation and hysteresis. Contraction by the elements of the cytoskeleton alone and in contact with the membrane imparts an active element to shape changes. It further complicates attempts to understand the cell

Life in space is exposed to microgravity (Todd, 1989). In particular, the effects of reduced gravity is still a lack of knowledge about the local structures of a cell which may react to gravity. Biological organization, genetics, morphological characteristics of single cell and whole organisms will be affected under microgravity conditions (Cogoli and Gumunder, 1991; Cogoli, et al., 1990). Space experiments represent the most spectacular segment in gravitational cell biology which the effects of gravity on living systems are studied (Schatz and Linke-Hommes, 1989; Hiramoto, 1990).

Numerous theories which model cell shape and cellular functions such as motility include these important factors (Vadgama, 1992; Gumunder and Cogoli, 1988); Mascio and Sudar, 1990). All understand that an accurate description

\footnotetext{
- Professor, Associate AlAA

* Senior Research Engineer

* Chief Scientist
}

of cell shape and related functions is most certainly a balance between the forces described above as well as others. The variation of gravity in a low level of gravitational acceleration have been shown to have an influence on all aspects of cell and organism shape, organization, genetics, and morphological characteristics including those involved in growth and development (Planel, et al., 1982; Nace, 1983, Cogoli, et al., 1984; Cogoli and Gumunder, 1991; Myshkis et al., 1987).

Time-dependent dynamical behavior of rotating bubble in reduced gravity environment were simulated by numerically solving the Navier-Stokes equations subject to the initial and the boundary conditions (Hung and Shyu, 1991 a,b,c; 1992 a,b,c; Hung and Leslie, 1988; Hung et al., 1989 $a, b ; 1990 a ; 1991 a, b, c ; 1992 a, b, c)$. Some of the steady-state formulations of bubble shapes, in particular for the bubble intersecting the top wall of the cylinder, were compared with the available experiments carried out by Leslie (1985) in a free-falling aircraft $(K C-135)$. In the $K C-135$ experiments, the background gravity is approximately $10^{-3} \mathrm{~g}_{0}\left(\mathrm{~g}_{0}=9.81 \mathrm{~m} / \mathrm{s}^{2}\right)$ during the $30 \mathrm{sec}$ low gravity period.

In the spacecraft orbit around the Earth, the direction of local background gravity varies from $0^{\circ}$ along the rolling axis of vehicle to various directions in which three dimensional calculation shall be assumed. In this study, the effect of asymmetric gravity acceleration exerted on the human cell with the direction of background gravity in $30^{\circ}, 45^{\circ}$ and $60^{\circ}$ measured from the vertical axis of the container are investigated. The purpose of this study is to investigate time sequence evolution of human cell deformation under various magnitudes of gravity acceleration. Both free floating cells and cells contacted to high and low inclined walls will be investigated.

Experimental observations of lymphocyte deformation throughout human cell shape change exposed to variable gravity levels from $10^{-3}$ to $2 g_{0}$ have been tested and observed in the Kc-135 aircraft. Model computation and experimental observations are compared.

\section{IL. Mathematical Model}

The present study examines time-dependent human cell behavior, in particular the dynamics of the human cell immersed inside the culture fluids imposed by the reduced gravity accelerations. In this study, a time-dependent three dimensional mathematical formulation is adopted.

Consider a circular cell of radius, $a$, immersed inside the culture liquid of constant density $\rho$ and viscosity $\mu$. Let us use cylindrical coordinates $(r, \theta, z)$, with corresponding velocity components $(u, v, w)$, and corresponding gravitational acceleration components $\left(g_{n}, g_{\theta}, g_{z}\right)$. The governing equations are shown as follows:

(A) Continuity Equation

$$
\frac{1}{r} \frac{\partial}{\partial r}(r u)+\frac{1}{r} \frac{\partial v}{\partial \theta}+\frac{\partial w}{\partial z}=0
$$


(B) Momentum Equations

$$
\begin{gathered}
\rho\left(\frac{\partial u}{\partial t}+u \frac{\partial u}{\partial r}+\frac{v}{r} \frac{\partial u}{\partial \theta}-\frac{v^{2}}{r}+w \frac{\partial u}{\partial z}\right)=-\frac{\partial \Phi}{\partial r}+\rho g_{r} \\
+\mu\left(\nabla^{2} u-\frac{u}{r^{2}}-\frac{2}{r^{2}} \frac{\partial v}{\partial \theta}\right) \\
\rho\left(\frac{\partial v}{\partial t}+u \frac{\partial v}{\partial r}+\frac{v}{r} \frac{\partial v}{\partial \theta}+\frac{u v}{r}+w \frac{\partial v}{\partial z}\right)=-\frac{1}{r} \frac{\partial p}{\partial \theta}+\rho g_{\theta} \\
+\mu\left(\nabla^{2} v-\frac{v}{r^{2}}+\frac{2}{r^{2}} \frac{\partial u}{\partial \theta}\right)
\end{gathered}
$$

$$
\rho\left(\frac{\partial w}{\partial t}+u \frac{\partial w}{\partial r}+\frac{v}{r} \frac{\partial w}{\partial \theta}+w \frac{\partial w}{\partial z}\right)=-\frac{\partial p}{\partial z}+\rho g_{z}+\mu \nabla^{2} w(2-4)
$$

where

$$
\nabla^{2}=\frac{1}{r} \frac{\partial}{\partial r}\left(r \frac{\partial}{\partial r}\right)+\frac{1}{r^{2}} \frac{\partial^{2}}{\partial \theta^{2}}+\frac{\partial^{2}}{\partial z^{2}}
$$

Let the profile of the interface between human cell and culture liquid be given by:

$$
\eta(t, r, \theta, z)=0
$$

The initial condition of the profile of the interface between human cell and culture liquid at $t=t_{0}$ is assigned explicitly, and is given by:

$$
\eta(t=t, r, \theta, z)=0
$$

A set of boundary conditions has to be supplied for solving the equations. These initial interface profiles used in this study have been given explicitly through the steady state computations made by Hung and Leslie (1992 a) and Hung et al (1990 b) which were checked by the experiments carried out by Leslie (1985). These boundary conditions are as follows

(1) Along the container wall, the following three boundary conditions apply:

(a) Interface between solid and culture liquid: Nopenetration and no-slip conditions assure that both the tangential and the normal components of the culture liquid velocity along the solid walls will vanish

(b) Interface between solid and cell: Similar nopenetration and no-slip conditions as that shown for interface between solid and cell will apply.

(c) At the location of solid-liquid-cell three phases interface: No - penetration, but not no-slip condition apply. This will assure that normal components of liquid and cell velocities along the solid wall vanish, and allow a slipping flow of liquid and cell fluids along the solid wall at three phase interface location. The velocity of slipping flow at this location is governed by the adhesive forces between fluids (culture liquid and cell) and solid walls. Also, at this location of three phase interface, a constant contact angle is present in which the behaviors of wet or dry contacts are determined by Coulomb interaction between the fluids (culture liquid and cell) and the surface phenomena (material and roughness) of solid walls.

(2) Along the interface between the cell and culture liquid and cell fluids, the following two conditions apply:

(a) Kinematic surface boundary condition: The cell surface moves with the cell which implies

$$
\frac{D n}{D t}=0, o r
$$$$
\frac{\partial \eta}{\partial t}+u \frac{\partial \eta}{\partial r}+\frac{v}{r} \frac{\partial \eta}{\partial \theta}+w \frac{\partial \eta}{\partial z}=0
$$

(b) Interface stress condition: Across the interface between blood cell and culture liquid,the stress must be continuous. Based on Landu and Lifshitz (1959), the stress across the cell-liquid interface can be expressed as

$\left(P_{c}-P_{L}\right) n_{i}-\left[\left(\tau_{1 j}\right) c^{-\left(\tau_{1 j}\right)}\right] n_{f}=\sigma\left(\frac{1}{R_{1}}+\frac{1}{R_{2}}\right) n_{i}(2-9)$

where $R_{1}$ and $R_{2}$ are the radius of curvatures of two major axes $n$ the point of interests along the cell-liquid interface. These $R_{4}$ and $R_{2}$ can be expressed in terms of the configuration of the cell-liquid interface in cylindrical coordinates as follows

$$
\frac{1}{R_{1}}+\frac{1}{R_{2}}=-\frac{1}{r}\left[\frac{\partial}{\partial r}\left(\frac{r H_{r}}{D}\right)+\frac{\partial}{\partial \theta}\left(\frac{H_{\theta}}{r D}\right)(2-10)\right.
$$

where the configuration of the cell-liquid interface is $z=H\left(t=t_{\alpha}, r, \theta\right) ; H_{t}=\partial H / \partial r ; H_{\theta}=\partial H / \partial \theta$, and $D=\left(1+H_{r}{ }^{2}\right.$ $\left.+H_{\theta}{ }^{2} / r^{2}\right)^{1 / 2}$. Here

$\tau_{1 j}=\mu\left(\frac{\partial u_{1}}{\partial x_{f}}+\frac{\partial u_{f}}{\partial x_{1}}+\frac{2}{3} \frac{\partial u_{k}}{\partial x_{k}} \delta_{1 j}\right)+\zeta \frac{\partial u_{k}}{\partial x_{k}} \delta_{i j}$

is the viscous stress tensor, $\mu$, the viscous coefficient of the first kind; $\zeta$, the viscous coefficient of the second kind; $P$, the pressure; $\sigma$, the surface tension of the cell-liquid interface; and $n_{j}$ the unit vector normal to the interface; and $\delta_{i j}$, the Kronecker delta function. Also, subscripts $C$ and $L$ denote conditions at cell and culture liquid fluids, respectivety, across the cell-liquid interface.

The fluid stresses across the celltiquid interface can be decomposed to the components normal and tangential to the interface. For the component tangential to the interface, one can take a dot product of a unit vector, $t$, to Equations (29) and (2-10), which leads to

$$
\left[\left(\tau_{1,} t_{1} n_{f}\right)\right]_{L}=\left[\left(\tau_{1 j} t_{1} n_{f}\right)\right]_{C}
$$


since $n_{i} t_{i}=0$.

For the component normal to the interface, one can also take a dot product of the unit vector normal to the interface, $n_{i}$, to Equations (2-9) and (2-10), which leads to

$$
\begin{gathered}
P_{c}-P_{L}-\left[\left(\tau_{1 j} n_{1} n_{f}\right)_{c}-\left(\tau_{1 j} n_{1} n_{j}\right)_{L}\right]= \\
-\frac{\sigma}{r}\left[\frac{\partial}{\partial r}\left(\frac{r H_{r}}{D}\right)+\frac{\partial}{\partial \theta}\left(\frac{H_{\theta}}{r D}\right)\right]
\end{gathered}
$$

Detailed descriptions of the computational algorithm applicable to cell-liquid dynamics under microgravity environment are given in our earlier studies (Hung et al., 1991 a,b; 1992 a, b, c; 1993 a,b,c; Hung and Pan, 1993; Hung and Shyu, $1993 a, b, c)$. In this study, a single human blood ceil with a radius of $10 \mu \mathrm{m}$ which is immersed in the infinite large volume of culture liquid has been used in the numerical simulation. Both the free floating cell and the cell contacted to the upper and lower inclined walls imposed by the timedependent reduced gravity acceleration are considered in this study. The temperature of the blood cell and culture liquid is $20^{\circ} \mathrm{C}$. In this study the following data were used: culture liquid density $=0.99823 \mathrm{~g} / \mathrm{cm}^{3}$, cell density $=1.00 \mathrm{~g} / \mathrm{cm}^{3}$, fluid pressure $=1.013 \times 10^{5} \mathrm{~N} / \mathrm{m}^{2}$, surface tension coefficient at the interface between cell and culture liquid $=8.3$ dyne $/ \mathrm{cm}$, culture liquid viscosity coefficient $=1.005 \times 10^{-2} \mathrm{~g} / \mathrm{cms}$, cell viscosity coefficient $=1.002 \times 10^{-2} \mathrm{~g} / \mathrm{cm}$ s, and contact angle $=$ $5^{\circ}$

A staggered grid for the velocity components is used in this computer program. The method was developed by Harlow and Welch (1965) for their MAC (marker and cell) method of studying fluid flows along a free surface. The finite difference method employed in this numerical study was the "Hybrid Scheme" developed by Spalding (1972). The formulation for this method is valid for any arbitrary interface location between the grid points and is not limited to middle point interfaces. An algonthm for a semi-implicit method (1980) was used as the procedure for modeling the flow field. The time step is determined automatically based on the size of the gnd points and the velocity of flow fields. A detailed description of the computational algorithm applicable to microgravity fluid behavior is illustrated in our earlier studies ${ }^{1 \cdot 15}$. Figures $1(A)$ and $t(B)$ show tme evolution of the variation of gravity acceleration in a linear scale and logarithmic scale, respectively, imposed on the blood cell and culture liquid. In this study, gravity acceleration varies from $10^{-3}$ to $2 \mathrm{~g}_{\mathrm{o}}\left(=9.81 \mathrm{~cm} / \mathrm{s}^{2}\right)$.

\section{Dynamical Behavior of Free Floatina Cell in Reduc Gravity}

Equations (2-1) to (2-4) have been solved numerically subjected to the initial condition, given in Equation (2-7), and boundary conditions, given in Equations (2-8) to (2-12). The initial condition of cell profile imposed by gravity acceleration of $10^{-3} \mathrm{~g}_{0}$ is a spherical shape floating freely immersed inside the culture liquid. For the case of free floating cell, gravity acceleration is always pointing toward the negative direction of the vertical $z$-axis which is perpendicular to the horizontal $r-\theta$ plane in cylindrical coordinates. Figure 2 shows the time sequence evolution of three dimensional free floating blood cell profiles at time $t=0,5,14$ and 15 seconds for corresponding variations of gravity acceleration with the magnitudes of $10^{-3}$. $1.26 \times 10^{-2}, 1.2$ and $2.0 \mathrm{~g}_{0}$ respectively. It shows that ceil shape changes from spherical and elongates horizontally to
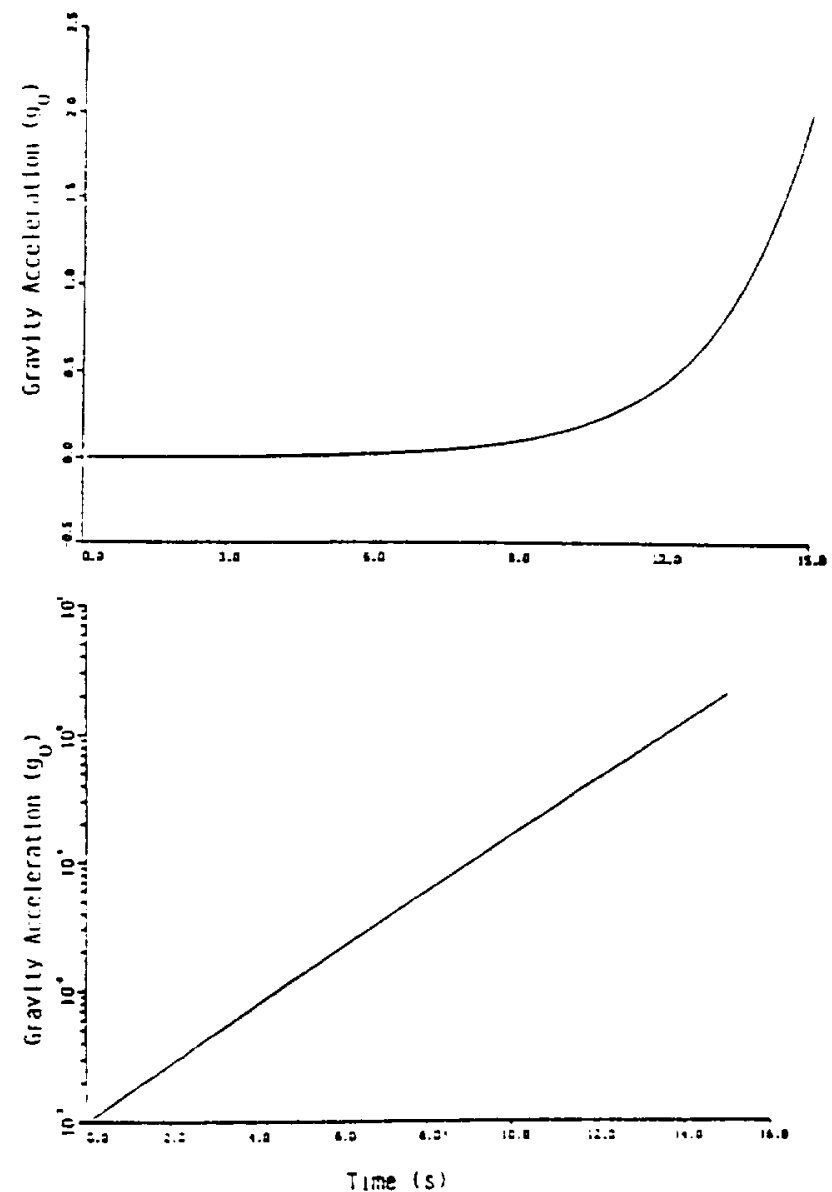

Figure 1 Time evolution of the variation of gravity acceieration imposed on human cell and culture liquid. (A) in linear scale, $(B)$ in loganithmic scale.

become ellipsoid when imposed gravity acceleration varies from $10^{-3}$ to $2 g_{0}$ in 15 seconds

Figure 3 shows the time sequence evolution of free floating cell profiles in the vertical $r-z$ plane cross-section at $\theta=$ 0 and $180^{\circ}$ at the same time variations and same corresponding variations of imposed gravity acceleration as that shown in Figure 2 . It shows clearly that the vertical crosssection of cell profile varies from circular and elongates horizontally to become elliptic shapes when imposed gravity acceleration changes from $10^{-3}$ to $2 \mathrm{~g}_{0}$ in 15 seconds.

Figure 4 shows time sequence evolution of free floating cell profiles in the other side of vertical $r-z$ plane crosssection at $\theta=90^{\circ}$ and $270^{\circ}$ at same time variations and same corresponding variations of imposed gravity acceleration as that shown in Figure 2. Similar to Figure 3, Figure 4 also illustrates the same trend of configuration variations of blood cell due to the effect imposed by the variation of gravity acceleration.

For the cross-section in the horizontal $r-\theta$ plane at different heights of vertical $z$-axis, the free floating cell profiles show a series of circular shapes with different radius in the time sequence evolution. In other words, the horizontal crosssection of the radius of circular cell profile increases as the imposed gravity acceleration changes from $10^{-3}$ to $2 \mathrm{~g}$ o in 15 seconds. 
(a) $t=0, g=1.0 \times 10^{-3} \omega_{0}$

(b) $t=5 . g=1.26 \times 10^{-2} 80$

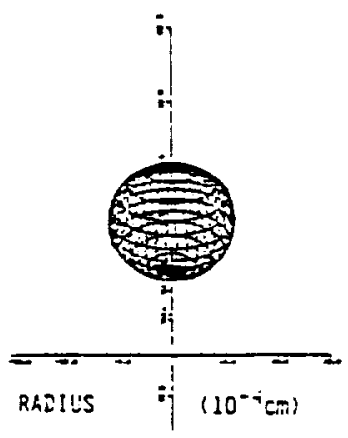

(c) $t=14 \mathrm{~s}, g=1.280$

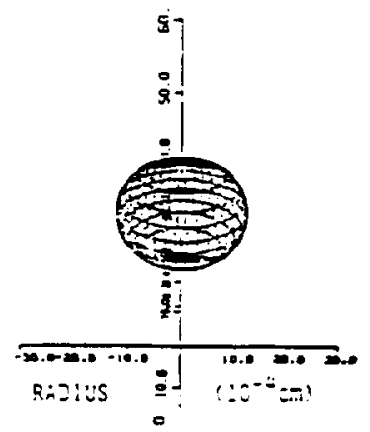

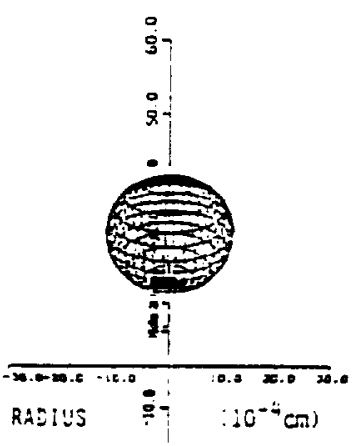

(d) $1=15 *, \theta=2.0 \%$

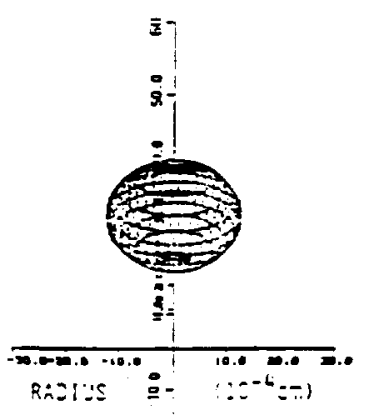

Figure 2 Time sequence evolution of free floating cell profiles in three dimensional configurations imposed by the corresponding vanation of gravity acceleration ranging from $10^{\circ}$ ${ }^{3}$ to $2 \mathrm{~g}_{\mathrm{o}}$ in 15 seconds.
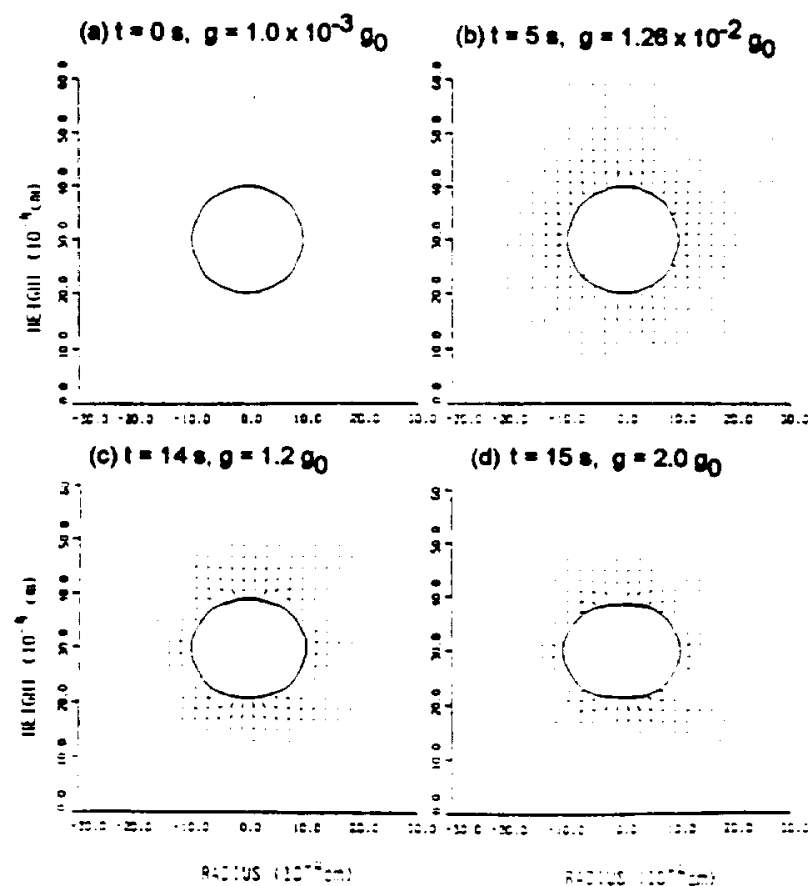

(d) $t=15 \approx, g=2.000$

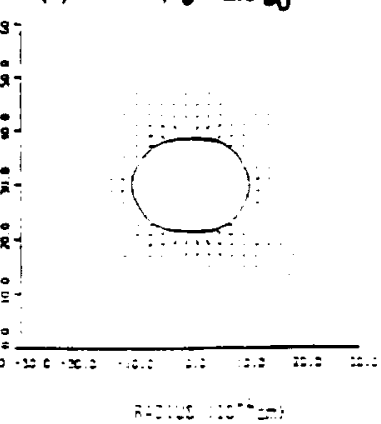

Figure 3 Time sequence evolution of free floating cell profiles in the vertical plane at $\theta=0^{\circ}$ and $180^{\circ}$, imposed by the corresponding variation of gravity acceleration ranging from 10 ${ }^{3}$ to $2 g_{0}$ in 15 seconds.
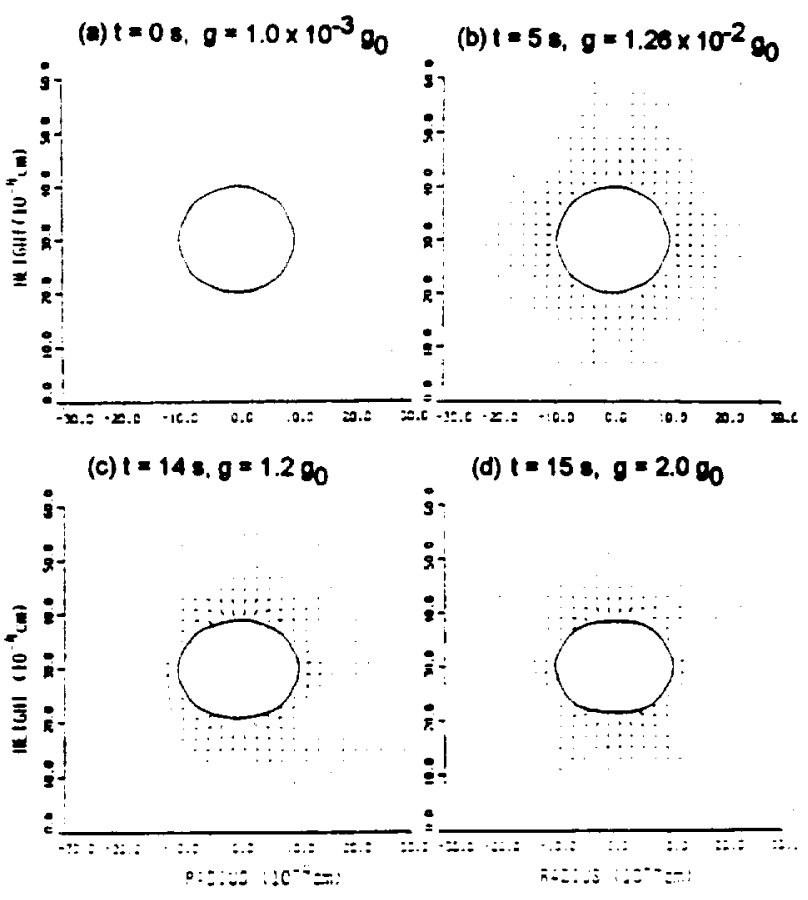

Figure 4 Time sequence evolution of free floating cell profiles in the vertical plane at $\theta=90^{\circ}$ and $270^{\circ}$, imposed by the corresponding variation of gravity acceleration ranging from $10^{\circ}$ ${ }^{3}$ to $2 g_{0}$ in 15 seconds.

\section{Dynamical Behavior of Lower Inclined Wall. Contacted Cell in Reduced Gravity}

Time sequence evolution of human cell immersed in culture liquid and contacted to the lower inclined wall imposed by the gravity acceleration which varies form $10^{-3}$ to $2 g_{0}$ in 15 seconds are investigated. Three different cases of inclined wall for angles between inclined plane wall and vertical z-axes at $30^{\circ}, 45^{\circ}$, and $60^{\circ}$ are studied. The inclined plane walts are awrays located at the plane of $\theta=90^{\circ}$ and $270^{\circ}$. Similar to free floating cell, gravity acceleration is also pointing toward the negative direction of the vertical $z$-axis which is perpendicular to the horizontal $r-\theta$ plane in cylindrical coordinates for this case.

Figures 5,6 and 7 show the time sequence evolution of lower $30^{\circ}$ inclined wall contacted cell profiles in the threedimensional configurations, in the vertical $r-z$ plane crosssection at $\theta=0^{\circ}$ and $180^{\circ}$, and in the vertical $r-z$ plane crosssection at $\theta=90^{\circ}$ and $270^{\circ}$, respectively, imposed by the corresponding variation of gravity acceleration ranging from $10^{-3}$ to $2 \mathrm{~g}_{0}$ in 15 seconds. These figures show the time sequence evolution of how spherical-shaped human cell sits on the lower $30^{\circ}$ inclined wall, gradually flaty elongates in horizontal direction, and finally becomes horizontally elongated ellipsoidshaped cell sitting on the lower $30^{\circ}$ inclined plane when the imposed gravity acceleration varies from $10^{-3}$ to $2 \mathrm{~g}_{0}$ in 15 seconds.

In order to save figures and descriptions, time sequence evolution of three-dimensional configurations and cross-sectional profiles in the vertical $r-z$ plane at $\theta=0^{\circ}$ and $180^{\circ}$ only will be presented in the rest of the animation of the time-dependent deformation of human cells exposed to variable gravity conditions.

Figures 8 and 9 show the similar time sequence 

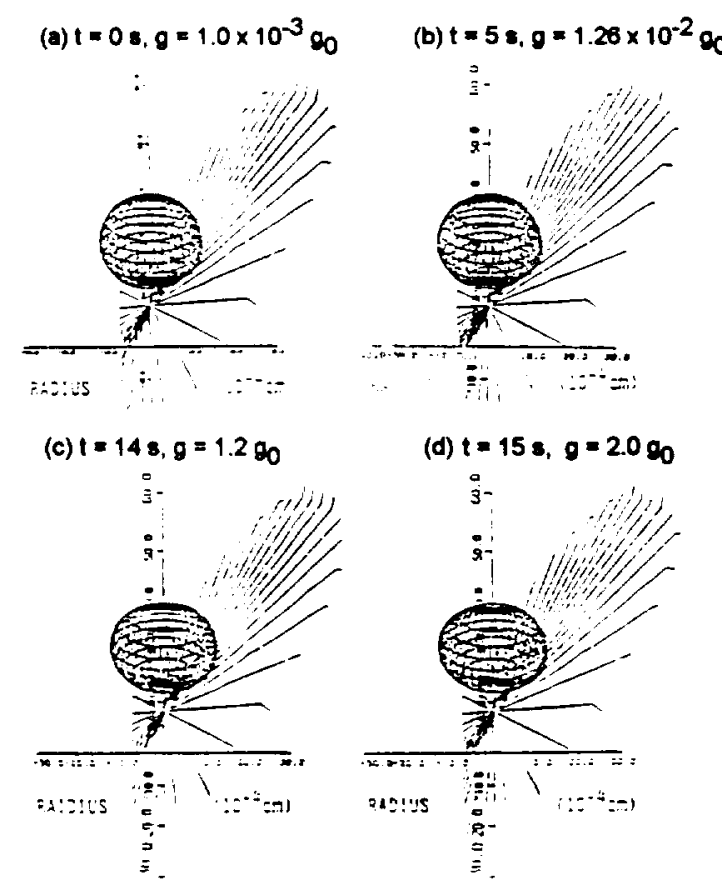

Figure 5 Time sequence evolution of lower $30^{\circ}$ inclined wall contacted cell profiles in three dimensional configurations, imposed by the corresponding variation of gravity acceleration ranging from $10^{-3}$ to $2 g_{0}$ in 15 seconds.

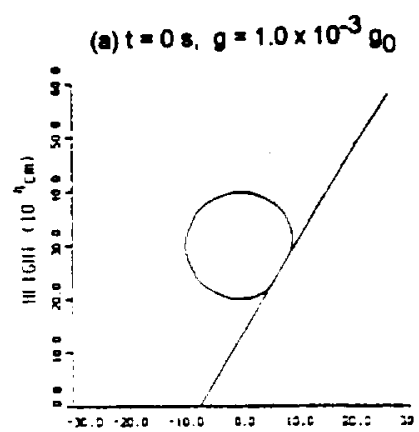

(b) $t=58, g=1.28 \times 10^{-2} 9$
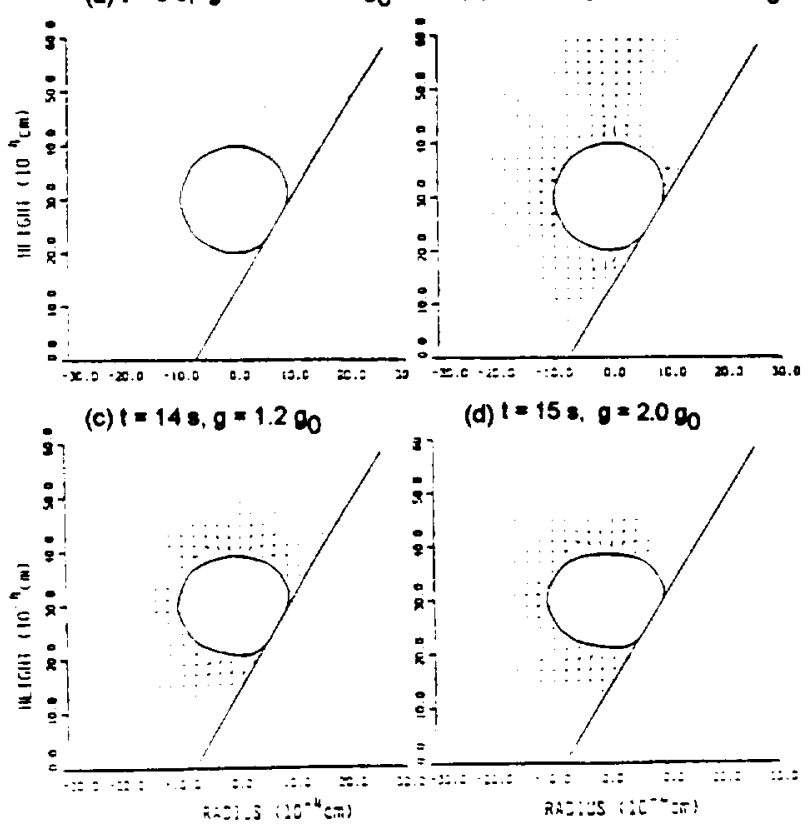

(d) $t=15 s, g=2.000$

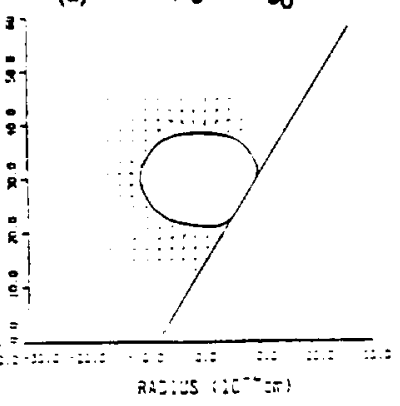

Figure 6 Time sequence evolution of lower $30^{\circ}$ inclined wall contacted cell profiles in the vertical plane at $\theta=0^{\circ}$ and $180^{\circ}$, imposed by the corresponding variation of gravity acceleration ranging from $10^{-3}$ to $2 g_{0}$ in 15 seconds.
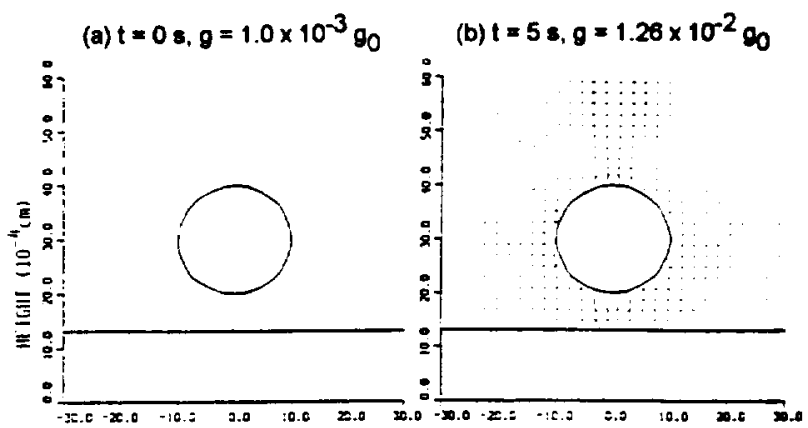

(c) $t=14 ., g=1.280$

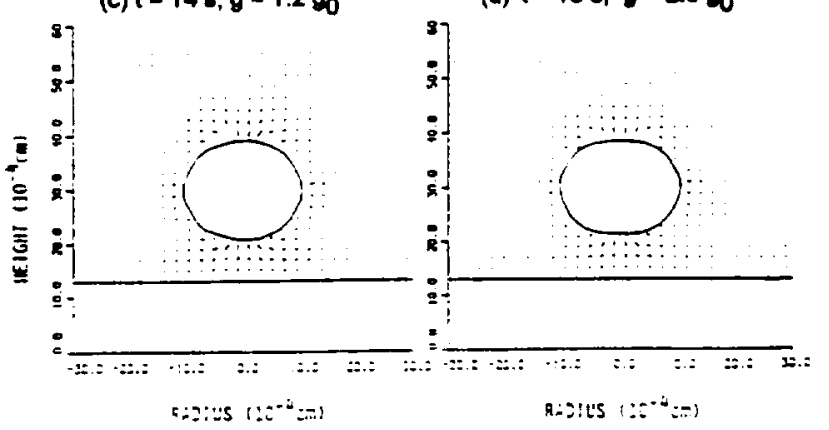

Figure 7 Time sequence evolution of lower $30^{\circ}$ inclined wall contacted cell profiles in the vertical plane at $\theta=90^{\circ}$ and $270^{\circ}$, imposed by the corresponding variation of gravity acceleration ranging from $10^{-3}$ to $2 g_{0}$ in 15 seconds.
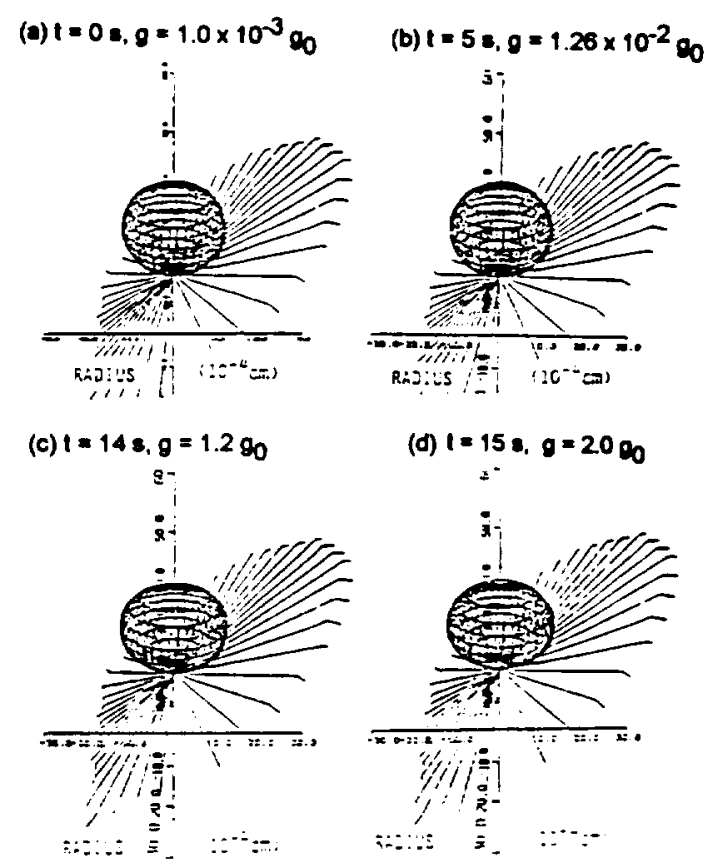

Figure 8 Time sequence evolution of lower $45^{\circ}$ inclined wall contacted cell profiles in three dimensional configurations, imposed by the corresponding variation of gravity acceleration ranging from $10^{-3}$ to $2 g_{0}$ in 15 seconds. 
evolution of lower $45^{\circ}$ inclined wall contacted cell profiles in the three-dimensional configurations, and in the vertical $r-z$ plane cross-section at $\theta=0^{\circ}$ and $180^{\circ}$, respectively, imposed by the corresponding variation of gravity acceleration ranging from $10^{\circ}$ to $2 \mathrm{~g}_{\mathrm{o}}$ in 15 seconds. Similar to Figures 5 to 7 . Figures 8 and 9 show the time sequence evolution of how a spherical-shaped human cell sits on the lower $45^{\circ}$ inclined wall changing from spherical-shaped to flatty elongated in horizontal direction ellipsoid-shaped as imposed gravity acceleration varies from $10^{-3}$ to $2 \mathrm{~g}_{0}$ in 15 seconds.

Figures 10 and 11 show similar time sequence evolution of lower $60^{\circ}$ inclined wall contacted cell profiles in the three-dimensional configurations, and in the vertical $r-z$ plane cross-section at $\theta=0^{\circ}$ and $180^{\circ}$, respectively, imposed by the corresponding vanation of gravity acceleration ranging from $10^{-5}$

to $2 \mathrm{go}$ in 15 seconds. Similar to Figures 5 to 7 for a human cell sitting on the lower $30^{\circ}$ inclined wall, and Figures 8 and 9 for human cell sitting on the lower $45^{\circ}$ inclined wall, Figures 10 and 11 show the time sequence evolution of how sphericalshaped human cell sits on the lower $60^{\circ}$ inclined wall changing from sphericalshaped to flatty elongated in horizontal direction ellipsoid-shaped as imposed gravity acceleration varies from $10^{-3}$ to $2 g_{0}$ in 15 seconds.

\section{$Y$ Dynamical Behavio of Upper inclined Wall Contacted Cell in Reduced Gravity}

Time sequence evolution of human cell immersed in culture liquid and hung on the upper inclined wall imposed by the gravity acceleration which varies from $10^{-3}$ to $2 g_{0}$ in 15 seconds are investigated. Three different cases of inclined wall for the angles between inclined plane wall and vertical $z$-axis at $30^{\circ}, 45^{\circ}$ and $60^{\circ}$ are studied. The inclined wall is atways located at the plane of $\theta=90^{\circ}$ and $270^{\circ}$. Similar to the previous cases, gravity acceleration is also pointing toward the negative direction of the vertical $z$-axis which is perpendicular to the horizontal $r-\theta$ plane in cylindrical coordinates for this case.

Figures 12 and 13 show the time sequence evolution of upper $30^{\circ}$ inclined wall contacted cell profiles in the threedimensional configurations, and in the vertical $r-z$ plane crosssection at $\theta=0^{\circ}$ and $180^{\circ}$, respectively, imposed by the corresponding variation of gravity acceleration ranging from $10^{-3}$

to $2 \mathrm{~g}_{0}$ in 15 seconds. These figures show time sequence evolution of how spherical-shaped human cell hangs to the $30^{\circ}$ inclined wall, gradually flatty elongates in the vertical direction, and finally becomes vertically elongated ellipsoid-shaped cell hanging to the inclined plane when the imposed gravity acceleration varies from $10^{-3}$ to $2 g_{0}$ in 15 seconds.

Figures 14 and 15 show the similar time sequence evolution of upper $45^{\circ}$ inclined wall contacted cell profiles in the three-dimensional configurations, and in the vertical $r-z$ plane cross-section at $\theta=0^{\circ}$ and $180^{\circ}$, respectively, imposed by the corresponding variation of gravity acceleration ranging from $10^{-3}$

to $2 g_{0}$. Similar to Figures 12 and 13 , Figures 14 and 15 show the time sequence evolution of how a spherical-shaped human cell hangs to the upper $45^{\circ}$ inclined wall changing from spherical-shaped to flatty elongated in vertical direction ellipsoid-shaped as imposed gravity acceleration varies from $10^{-3}$ top $2 \mathrm{~g}_{0}$ in 15 seconds.

Figures 16 and 17 show the similar time sequence evolution of upper $60^{\circ}$ inclined wall contacted cell profiles in the three-dimensional configurations, and in the vertical $r-z$ plane cross-section at $\theta=0^{\circ}$ and $180^{\circ}$, respectively, imposed by the corresponding variation of gravity acceleration ranging from $10^{.3}$

to $2 g_{0}$ in 15 seconds. Similar to Figures 12 and 13 for human cell hanging to upper $30^{\circ}$ inclined wall, and Figures 14
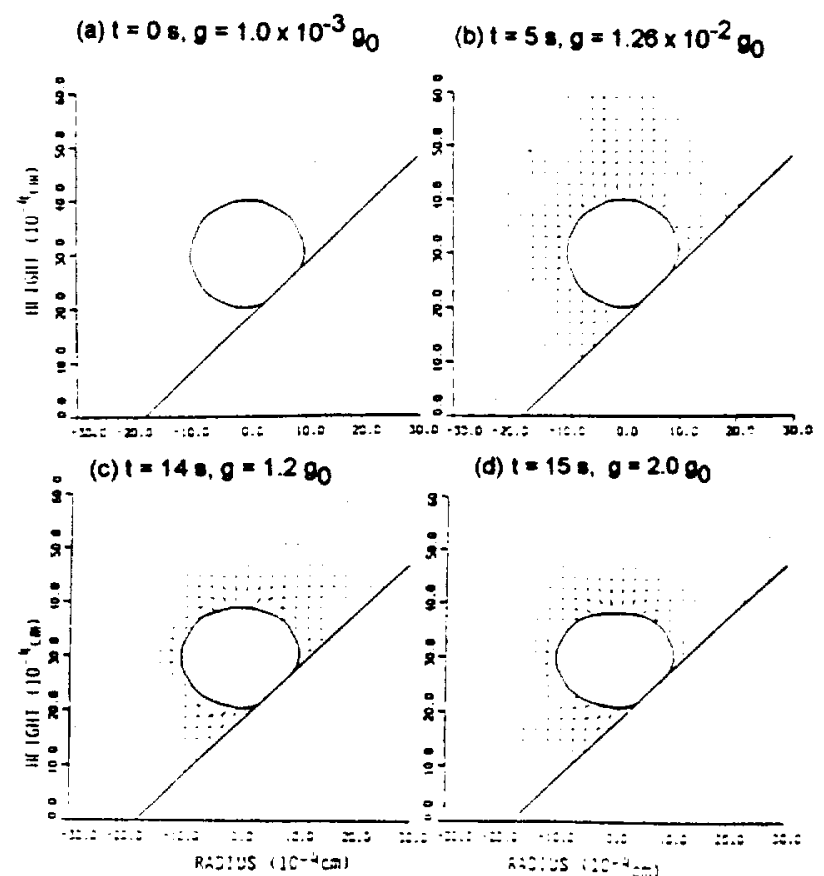

(d) $l=15, g=2.090$

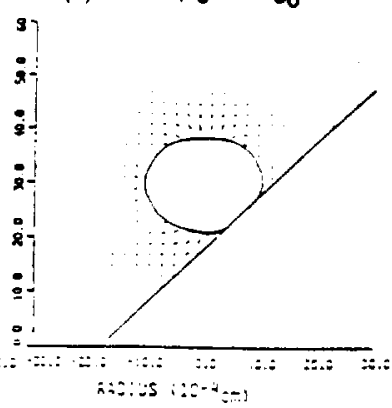

Figure 9 Time sequence evolution of lower $45^{\circ}$ inclined wall contacted cell profiles in the vertical plane at $\theta=0^{\circ}$ and $180^{\circ}$, imposed by the corresponding variation of gravity acceleration ranging from $10^{-3}$ to $2 g_{0}$ in 15 seconds.
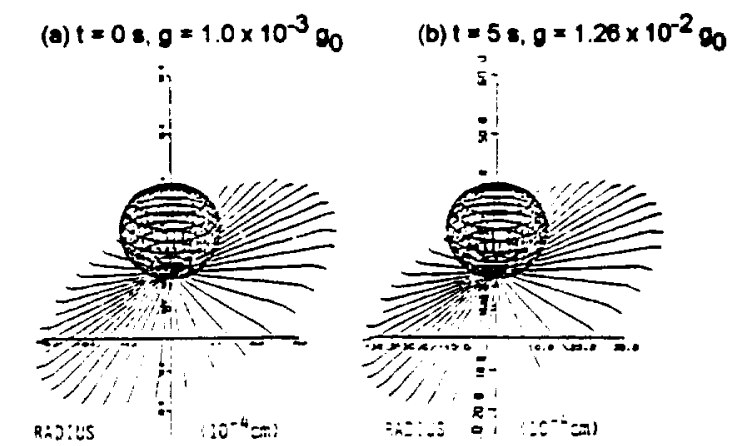

(c) $t=14 \mathrm{~s}, g=1.290$

i-

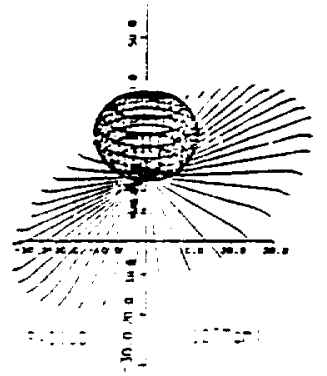

(d) $f=15 s, g=2.0 \mathrm{~g}$

iे

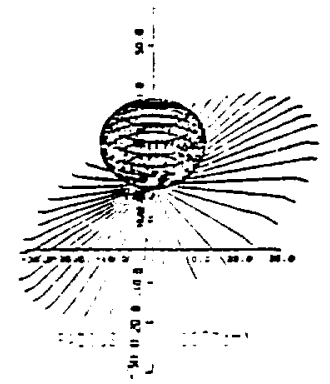

Figure 10 Time sequence evolution of lower $60^{\circ}$ inclined wall contacted cell profiles in three dimensional configurations, imposed by the corresponding variation of gravity acceleration ranging from $10^{-3}$ to $2 \mathrm{~g}_{0}$ in 15 seconds. 
(a) $t=0$ s, $g=1.0 \times 10^{-3} 90$

(b) $l=5 \mathrm{~s}, g=1.26 \times 10^{-2} 90$
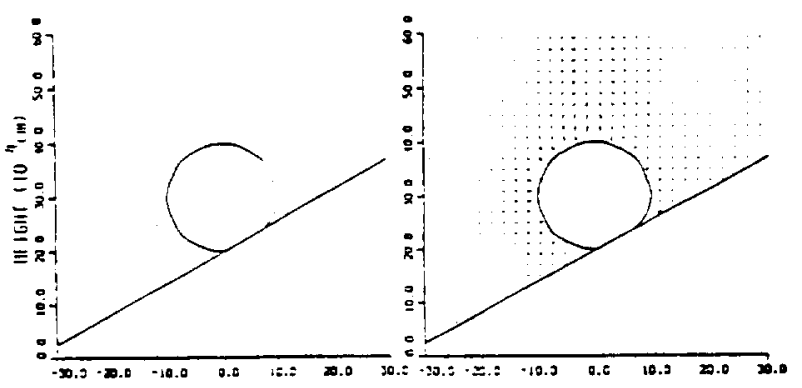

(c) $t=148, g=1.290$

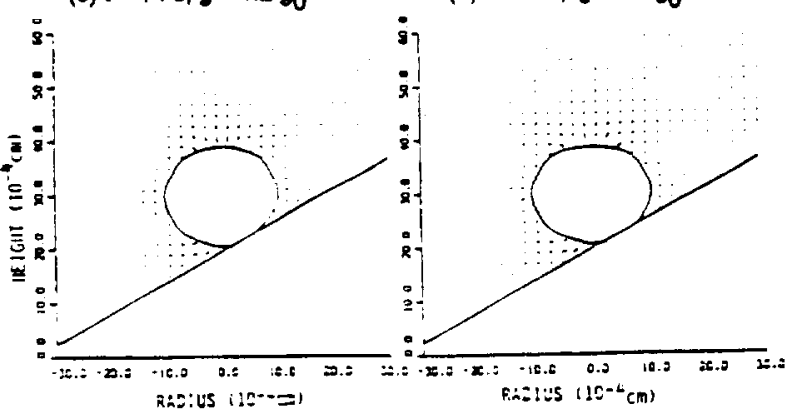

Figure 11 Time sequence evolution of lower $60^{\circ}$ inclined wall contacted cell profiles in the vertical plane at $\theta=0^{\circ}$ and $180^{\circ}$, imposed by the corresponding variation of gravity acceleration ranging from $10^{-3}$ to $2 g_{0}$ in 15 seconds.
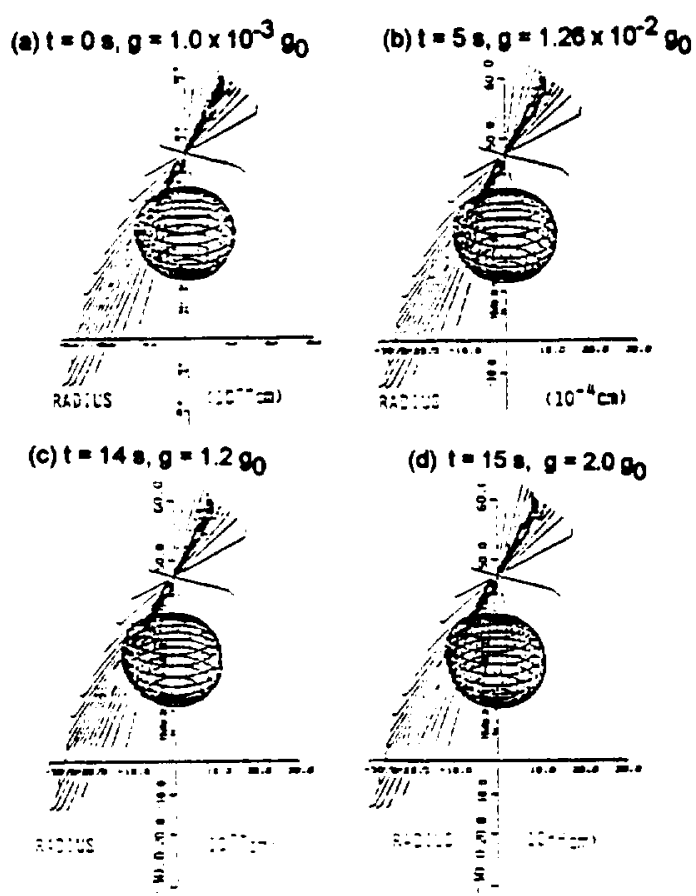

Figure 12 Time sequence evolution of upper $30^{\circ}$ inclined wall contacted cell profiles in three dimensional configurations. imposed by the corresponding variation of gravity acceleration ranging from $10^{-3}$ to $2 g_{0}$ in 15 seconds. (a) $t=08, g=1.0 \times 10^{-3} \mathrm{~g}_{0}$

(b) $1=58, g=1.26 \times 10^{-2} 80$
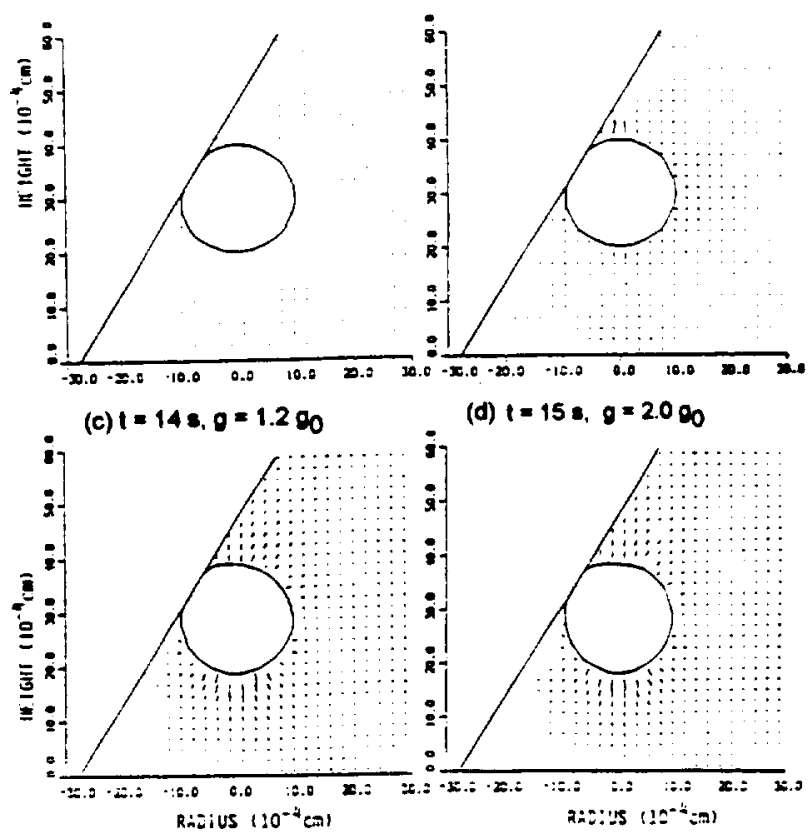

(d) $t=15 \& g=2.000$

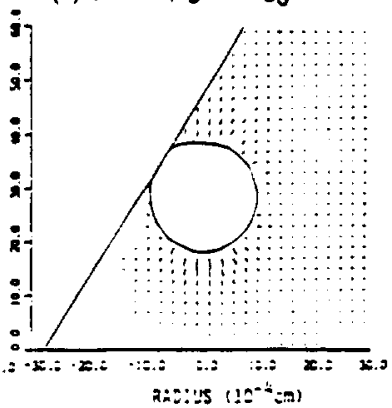

Figure 13 Time sequence evolution of upper $30^{\circ}$ inctined wall contacted cell profiles in the vertical plane at $\theta=0^{\circ}$ and $180^{\circ}$, imposed by the corresponding variation of gravity acceleration ranging from $10^{3}$ to $2 \mathrm{go}$ in 15 seconds.
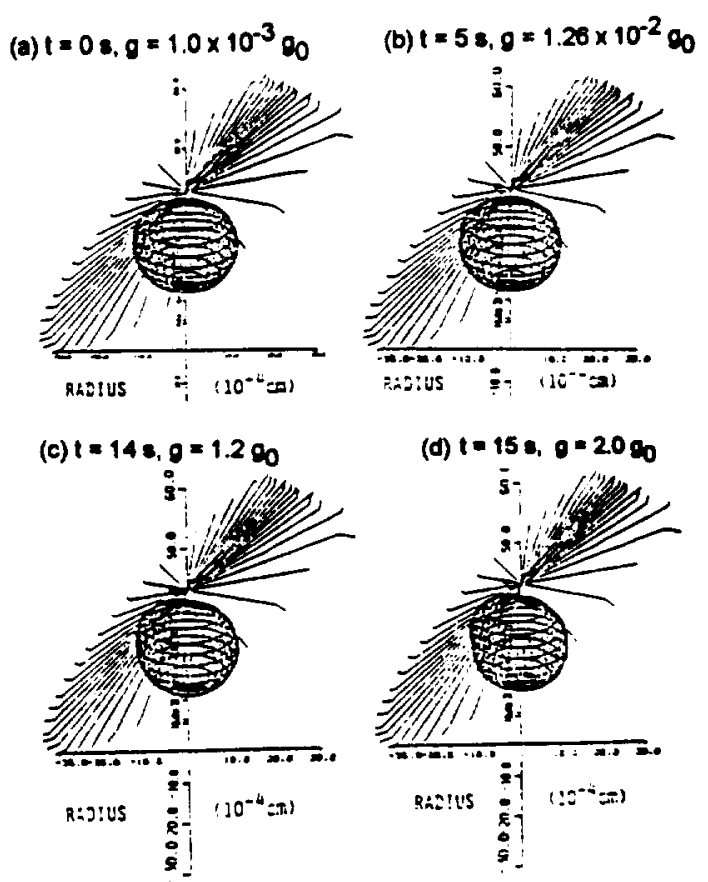

Figure 14

Time sequence evolution of upper $45^{\circ}$ inclined wall contacted cell profiles in three dimensional configurations, imposed by the corresponding variation of gravity acceleration ranging from $10^{-3}$ to $2 g_{0}$ in 15 seconds. 
(a) $t=0.8=1.0 \times 10^{-3} 80$

(b) $t=5 \mathrm{~s}, g=1.26 \times 10^{-2} 90$

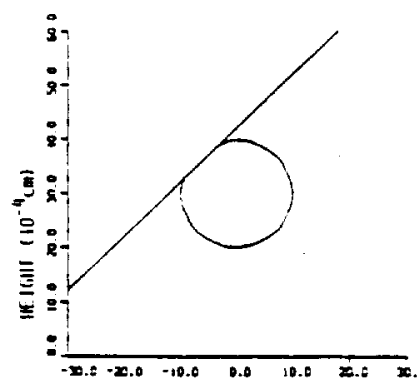

(c) $t=148, g=1.290$
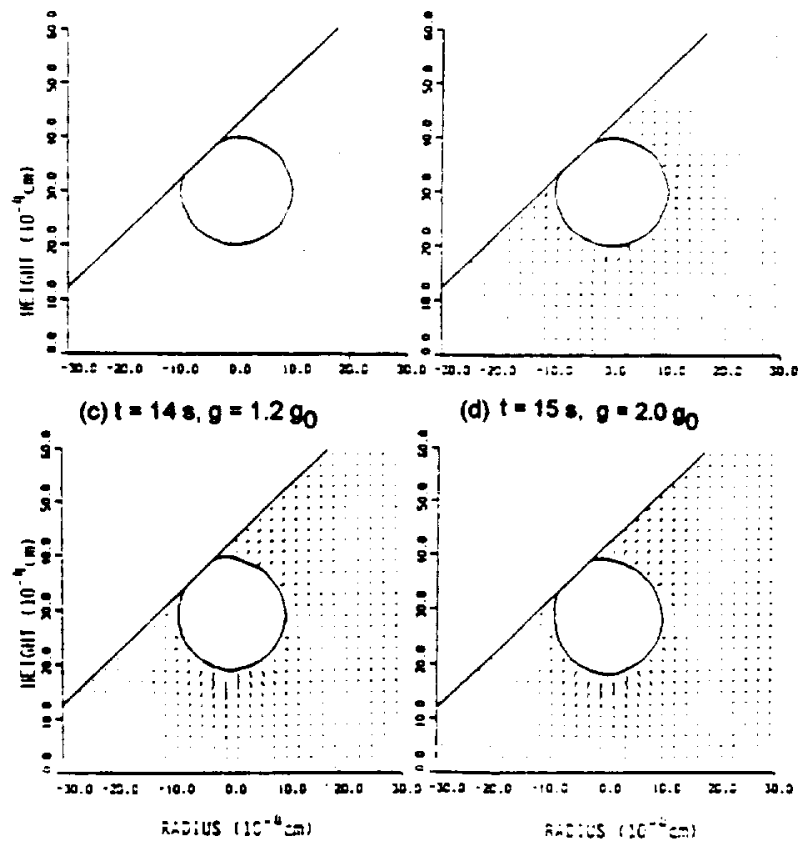

(d) $t=15 s, 0=2.080$

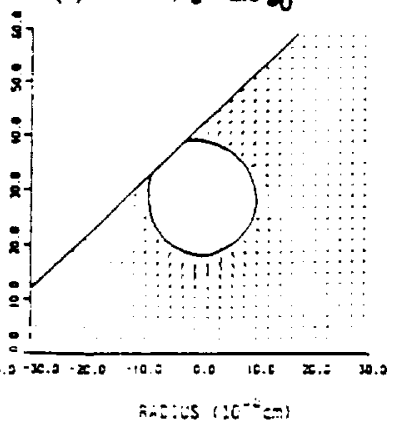

Figure 15 Time sequence evolution of upper $45^{\circ}$ inclined wall contacted cell profiles in the vertical plane at $\theta=0^{\circ}$ and $180^{\circ}$, imposed by the corresponding variation of gravity acceleration ranging from $10^{-3}$ to $2 \mathrm{~g}$ in 15 seconds.
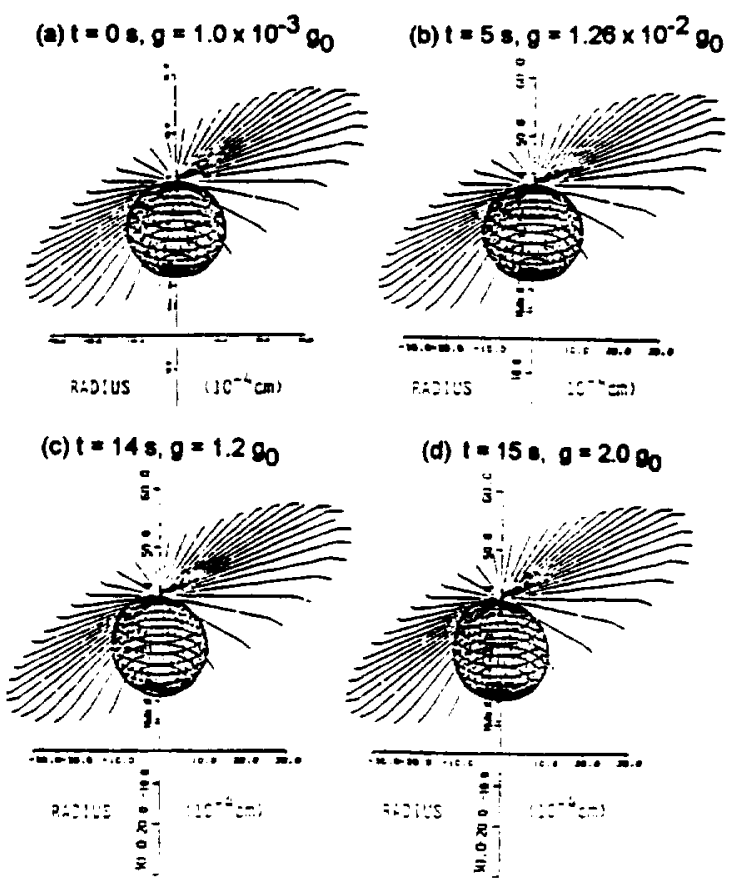

Figure 16 Time sequence evolution of upper $60^{\circ}$ inclined wall contacted cell profiles in three dimensional configurations, imposed by the corresponding variation of gravity acceleration ranging from $10^{-3}$ to $2 g_{0}$ in 15 seconds. (a) $1=0.8, g=1.0 \times 10^{-3} 90$

(b) $t=58, g=1.26 \times 10^{-2} 9$

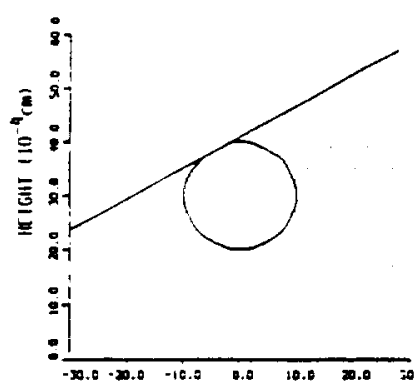

(c) $t=148, g=1.200$
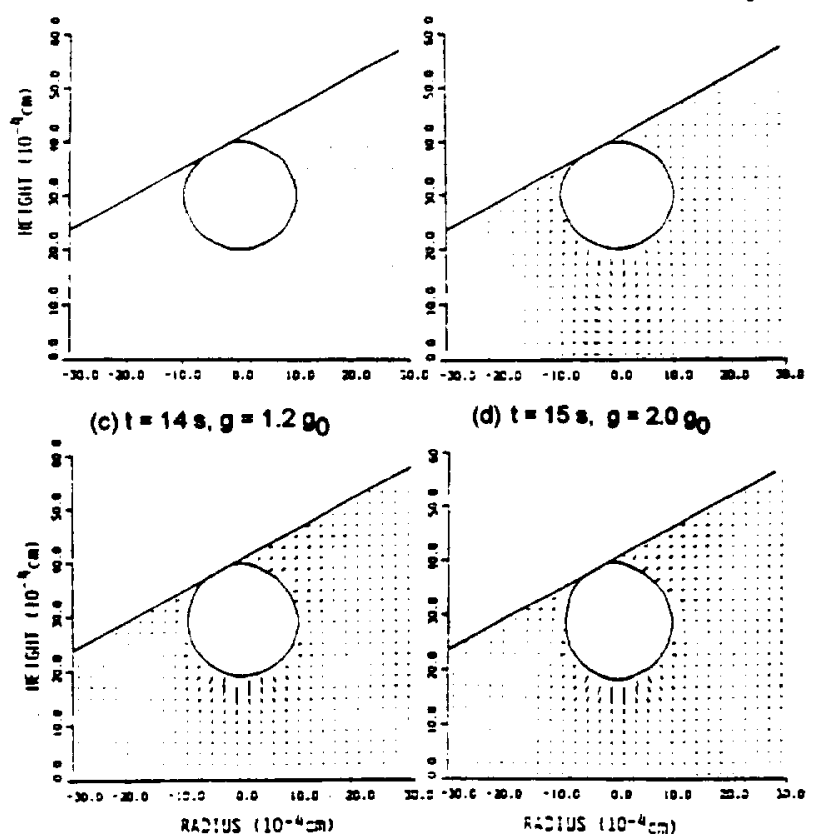

(d) $t=158, \theta=20 \%$

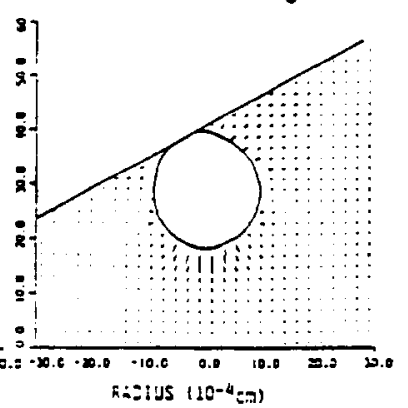

Figure 17 Time sequence evolution of upper $60^{\circ}$ inclined wall contacted cell profiles in the vertical plane at $\theta=0^{\circ}$ and $180^{\circ}$, imposed by the corresponding variation of gravity acceleration ranging from $10^{-3}$ to $2 \mathrm{~g}_{\circ}$ in 15 seconds.

and 15 for human cell hanging to upper $45^{\circ}$ inclined wall, Figures 16 and 17 show the time sequence evolution of how a spherical-shaped humar, cell hangs to the upper $60^{\circ}$ inclined wall changing from spherical-shaped to flatty elongated in vertical direction ellipsoid-shaped as imposed gravity acceleration varies from $10^{-3}$ to $2 \mathrm{~g}_{0}$ in 15 seconds.

The free-fall aircraft, $K C-135$, was used to test ymphocyte deformation through human cell shape change during the gravity level variation from $10^{-3}$ to $2 \mathrm{~g}$ 。 in fight. The experiment was carried out by Krug Life Sciences of Houston, Texas with sponsorship of the Biotechnology Program, NASA Johnson Space Center. The experimental observation shows that the cell shape appeared to have a "flattened" appearance during the period of time when gravity changed from $10^{-3}$ to $29_{0}$. These experimental results of cell deformation agree exactly with the theoretical model described above.

\section{Yl. Discussion and Conctusion}

The dynamical behavior of the configurations of human cell immersed in the culture liquid affected by the time dependent variation of gravity acceleration ranging from $10^{-3}$ to $2 g_{0}$ in 15 seconds have been investigated by numerically solving time-dependent three-dimensional Navier-Stokes equations subject to the initial and boundary conditions. Both free floating cell and cell contacted to upper and lower inclined walls imposed by the time-dependent reduced gravity acceleration are considered in this study. Three different cases of inclined wall for angles between inclined plane wall and vertical $z$-axis at $30^{\circ}, 45^{\circ}$ and $60^{\circ}$ are studied.

The following conclusions are drawn for the variation of human cell configurations as the gravity acceleration 
changes from $10^{-3}$ o $2 g_{0}$ based on the numerical simulation: (1) For the case of free floating cell immersed in the culture liquid, the vertical cross-section of the cell configuration changes from spherical and elongates horizontally to become horizontally elongated ellipsoid as gravity acceleration increases; (2) For the case of lower inclined wall contacted cell immersed in the culture liquid, the vertical cross-section of the cell configuration also changes from spherical and elongates horizontally to become horizontally elongated ellipsoid sitting on lower inclined wall as gravity acceleration increases; (3) For the case of the upper inclined wall contacted cell immersed in the culture liquid, the vertical cross-section of cell configuration changes from spherical and elongates vertically to become vertically elongated eilipsoid hung to the upper inclined wall as gravity acceleration increases; (4) For free floating cell and both lower and upper inclined walls contacted cells immersed in the culture liquid, the horizontal cross-section of cell configurations are all in circular-shaped; however, the diameter of both free floating and lower inclined wall contacted cell, measured in horizontal direction or vertical to gravitational force direction increases as gravity acceleration increases while the diameter of the upper inclined wall contacted celi, also measured in horizontal direction, decreases as the gravity acceleration increases; (5) On the contrary to Item (4), the shapes of vertical cross-section (or cross-section along the direction of gravity force) for free floating cell and both lower and upper inclined wall contacted cells are all in the form of elliptical-shaped; however, the major axis of ellipsoidal shaped cell are along the horizontal direction for free floating cell and lower inclined wall contacted cell while the major axis of ellipsoidal shaped cell is along the vertical direction for upper inclined wall contacted cell; and (6) For both lower and upper inclined walls contacted cells immersed in the culture liquid, the length of the ellipsoid-shaped cell along the major axis is greater for the smaller angles of lower inclined wall contacted cell sitting on the plane while the length of the ellipsoid-shaped cell along the major axis is smaller for the smaller angles of the upper inclined wall contacted cell hanging to the plane.

Experimental observation, carried out in the $\mathrm{KC}-135$ free-fall aircraft test of the deformation of human cells exposed to the variation of gravity levels, show that the results of experimental observations agree exactly with the theoretical model computation described in this paper.

The results of the present study show that the timedependent variation of gravity acceleration will affect the configurations of the human cells. This study demonstrates the significance of biological organization, genetics, morphological characteristics of single cell and whole organisms will be deeply affected under microgravity conditions.

\section{Acknowledgements}

The authors appreciate the support received from Krug Life Sciences through contract number P.O. 70511 and NASA Johnson Space Center. They would like express their gratitude to G. F. Spaulding and J. W. Janson of NASA Johnson Space Center.

\section{References}

Cogoli, A., Birgitt, C., and Lorenzi R., Response of Cells to Microgravity, Fundamentals of Space Bioleay (Asashima, M., and Malacinski, G. M., ed.,) pp. 97-112, Springer-Verlag, New York, 1990.

Cogoli, A., and Gumunder, F. K., Gravity Effects on Single
Cells, Advances in Space Biologr and Medicine (Bonting. S. L. ed. Vol. 1, pp. 183-248, JAl Press, London, 1991.

Cogoli, A. Tschopp, and Fuchs-Bislin, P., Cell Sensitivity to Gravity, Science, pp. 228-230, July, 1984.

Gumunder, F. K., and Cogoli, A., Cultivation of Single Cells in Space, Applied Microgravity Technology, Vol. 1, No. 3, pp. $115-122,1988$

Harlow, F. H., and Welch, J. E., Numerical Calculation of TimeDependent Viscous Incompressible Flow of Fluid With Free Surface, Physics Fluids, Vol. 8, pp. 2182-2193, 1965.

Hiramoto, Y., Evaluation of Cytomechanical Properties, Crtomechanics - The Mechanical Basis of Cell Form and Structure (Berei-Hahn, J., Anderson, O. R., and Reif, W. E., eds.), pp. 31-46, Spinger-Verlag, New York, 1990.

Hung, R. J., Lee, C. C., and Leslie, F. W., Effect of G-Jitters on the Stability of Rotating Bubble Under Microgravity Environment, Acta Astronautica, Vol. 21, pp. 309-321, 1990a.

Hung, R. J., Lee, C. C., and Leslie, F. W., Slosh Wave Excitation in a Partially Filled Rotating Tank Due to Gravity Jitters in a Microgravity Environment, Acta Astronautica, Vol. 25. pp. 523-551, 1991 a.

Hung, R. J., Lee, C. C., and Leslie, F. W., Response of Gravity Level Fluctuations on the Gravity Probe-B Spacecraft Propellant System, Journal of Propulsion and Power, Vol. 7, pp. 556-564, 1991b.

Hung, R. J., Lee, C. C., and Leslie, F. W., Spacecraft Dynamical Distribution of Fluid Stresses Activated by Gravity Jitter Induced Slosh Waves, Journal of Guidance. Control and Drnamics, Vol. 15, pp. 817-824, 1992a

Hung, R. J., Lee, C. C., and Leslie, F. W., Similarity Rules in Gravity Jitter- Related Spacecraft Liquid Propellant Slosh Waves Excitation, Journal of Fluids and Structures, Vol. 6, pp. 493-522, $1992 b$.

Hung, R. J., Lee, C. C., and Leslie, F. W., Effect of the Baffle on the Spacecraft Fluid Propellant Viscous Stress and Moment Fluctuations, Iransaction of the Japan Society for Aeronautical and Space Sciences, 35, 187-207, 1993a.

Hung, R. J., Lee, C.C., and Leslie, F. W., Effect of the Baffle on the Asymmetric Gravity-Jitter Excited Slosh Waves and Spacecraft Moment and Angular Momentum Fluctuations, Joumal of Aerosoace Enoineering (United Kingdom), in press, 1993b.

Hung, R. J., and Lee, C. C., Effect of the Baffle on On-Orbit Spacecraft Fluid System Angular Momentum Fluctuations and Action of Viscous Stress Moment Exerted on the Container, Proceed National Science Council, (A), 17, in press, 1993c.

Hung, R. J., Lee, C. C., and Shyu, K. L., Reorientation of Rotating Fluid in Microgravity Environment With and Without Gravity Jitters, Journal of Spacecraft and Rockets, Vol. 28, pp. $71-79,1991 \mathrm{c}$

Hung, R. J., and Leslie, F. W., Bubble Shapes in a Liquid-Filled Rotating Container Under Low Gravity, Journa Lo Spacecraft andRockets, Vol. $25, \quad$ pp. $70-74,1988$. 
Hung, R. J., Pan, H. L., and Leslie, F. W. Gravity Gradient or Gravity Jitter Induced Viscous Stress and Moment Fluctuations in Microgravity, Eluid Drmamics Research, in press 1993d.

Hung, R. J., and Pan, H. L., Asymmetric Slosh Wave Excitation in Liquid-Vapor Interface Under Microgravity. Acta Mechanica Sinica, in press, 1993.

Hung, R. J., and Shyu, K. L., Cryogenic Hydrogen Reorientation and Geyser Initiation at Various Liquid-Filled Levels in Microgravity, Advances in Space Research, Vol. 11(7), pp. 217-226, $1991 \mathrm{a}$.

Hung, R. J., and Shyu, K. L., Cryogenic Liquid Hydrogen Reorientation Activated by High Frequency Impulsive Reverse Gravity Acceleration of Geyser Initiation, Microgravity Quarterty, Vol. 1(2), pp. 81-92, $1991 \mathrm{~b}$.

Hung, R. J., and Shyu, K. L., Space-Based Cryogenic Liquid Hydrogen Reorientation Activated by Low Frequency Impulsive Reverse Gravity Thruster of Geyser Initiation, Acta Astronautica, Vol. 25, pp. 709-719, 1991c.

Hung, R. J., and Shyu, K. L., Constant Reverse Thrust Activated Reorientation of Liquid Hydrogen with Geyser Initiation, Joumal of Soacecraft and Rockets, Vol. 29, pp. 279285, 1992a.

Hung, R. J., and Shyu, K. L., Excitation of Slosh Waves Associated with Low Frequency Impulsive Reverse Gravity Acceleration of Geyser Initiation, Acta Astronautica, Vol. 26, pp. 425-433, 1992b.

Hung, R. J., and Shyu, K. L., Medium Frequency Impulsive Thrust Activated Liquid Hydrogen Reorientation with Geyser, Journal of Propulsion and Power, Vol. 8, pp. 987-994, $1992 \mathrm{c}$.

Hung, R. J., and Shyu, K. ., Suction Dip, Liquid Residual and slosh Wave Excitation during Liquid Draining in Microgravity, Advances in Soace Research, 13(7), 147-154, 1993a.

Hung, R. J., and Shyu, K. L., Liquid Settlement, Resettlement, Slosh Wave Excitation and Geyser Motion During Reorientation in Microgravity, Adyances in Space Research, 13(7), 155-163, 1993b

Hung, R. J., and Shyu, K. L., Liquid Resettlement and Slosh Wave Excitation During Fluid Reorientation in Microgravity, Acta Astronautica. 27, in press, 1993c.

Hung, R. J., Shyu, K. L., and Lee, C. C., Medium Frequency Impulsive Thrust Excited Slosh Waves During Propellant Reorientation with Geyser, Journal of Propulsion and Power, Vol. 8 , pp. $778-785,1992$ c.

Hung, R. J., Shyu, K. L., and Lee, C. C., Liquid Hydrogen Slosh Wave Excited by Constant Reverse Gravity Acceleration of Geyser Initiation, Journal of Spacecraft and Rockets, Vol. 29, pp. 523-528, 1992d.

Hung, R. J., Tsao, Y. D., Hong, B. B., and Leslie, F. W., Dynamics of Surface Tension in Microgravity Environment, Progress in Aeronautics and Astronautics, Vol. 127, pp. 124$150,1990 \mathrm{~b}$.
Hung, R. J., Tsao, Y. D., Hong, B. B., and Leslie, F. W., Dynamical Behavior of Surface Tension on Rotating Fluids in Low and Microgravity Environments, International Journal for Microgravity Research and Applications, Vol. 11, pp. 81-95, $1989 a$.

Hung, R. J., Tsao, Y. D., Hong, B. B., and Leslie, F. W., Axisymmetric Bubble Profiles in a Slowly Rotating Helium Dewar Under Low and Microgravity Environments, Acta Astronautica, Vol. 19, pp. 411-426, 1989b.

Hung, R. J., Tsao, Y. D., Hong, B. B., and Leslie, F. W., Bubble Behaviors in a Slowly Rotating Helium Dewar in Gravity Probe-B Spacecraft Experiment, Journat of Spacecraft and Rockets, Vol. 26, pp. 167-172, 1989c.

Landau, L. D., and Lifshitz, Eluid Mechanics, Pergamon Press, London, pp. 1-656, 1959.

Leslie, F. W., Measurements of Rotating Bubble Shapes in a Low Gravity Environment, Journal of Fluid Mechaniss, Vol. 161, pp. 269-275, 1985.

Mascio, L. N., and Sudar, D., Automatic Segmentation and Measurement of Cells in Three Dimension, New Technology in Cytometry and Molecular Biolooy (Salzman, G. C., ed.) SPIE, Vol. 1206, pp. 50-58, SPIE, Bellingham, Washington. 1990 .

Myshikis, A. D., Babskii, V. G., Kopachevskii, Slobozhanin, L. A., and Tyuptsov, A. D., Low Gravity Fluid Mechanics. Springer-Verlag, New York, 1987.

Nace, G. W., Gravity and Positional Homestasis of the Cell, Advences in Space Research, Vol. 3, No. 9, pp. 159-168, 1983.

Patankar, S. V., Numerical Heat Transfer and Fluid Flow, Hemisphere-McGraw-Hill, New York, pp. 197, 1980.

Patankar, S. V., and Spalding S. D., A Calculation Procedure for Heat, Mass and Momentum Transfer in Three Dimensional Parabolic Flows, International Journal of Heat Mass Iransfer, Vol. 15, pp. 15-24, 1972.

Planel, H., Tixador, R., Nefedov, Y. Gretchko, G. and Richoilley, G., Effects of Space Fight Factors at the Cellular Level: Results of the Cytos Experiment, Aviation. Soace,and Environmental Medicine, pp. 370-374, April 1982.

Schatz, A., and Linke-Hommes, A., Gravity and the MembraneSolution Interface: Theoretical Investigations, Adyances in Space Research, Vol. 9, No. 11, pp. 61-64, 1989.

Spalding, D. B., A Novel Finite-Difference Formulation for Differential Expressions Invohing Both First and Second Derivatives, International Journal of Numerical Methods in Enaineering, Vol. 4, pp. 551-563, 1972.

Todd, P., Gravity-Dependent Phenomena at the Scale of the Single Cell, ASGSB Bulletin, Vol. 2, pp. 95-115, August, 1989.

Vadgama, P., Opportunities for the Cellular Approach in Biomedical Engineering, Medicaland Biological Enoineering and Computation, Vol. 30, pp. CE2-CE7, 1992. 